Original Article

Krishna Sharma, MS, DNB Department of Neurosurgery Nepal medical college

Kathmandu, Nepal

Address for correspondence: Krishna Sharma, MS, DNB Department of Neurosurgery Nepal medical college Kathmandu, Nepal

Email: krishnasharma@yahoo.com

Received, January 20, 2016 Accepted, February 15, 2016

\section{Transpedicular Approach for Subaxial Cervical Spine}

Cervical spine decompression, fusion and fixation are required when pathologies like trauma, degeneration, infection or tumor destabilizes the spine or cause compression on neurovascular structures. Many approaches and instrumentation technique have evolved to achieve a stable spine closest to its natural state, preserving the anatomy and the function. Transpedicular approach to cervical spine has been a new addition to the attempt. Here, our experience of the procedure is presented.

Total of 38 cases underwent this procedure from 2014 February to 2015 December. Twenty-four cases had unstable spine due to trauma, twelve had severe multilevel spondylotic cord compression and two had dump bell schwannomas. Their age ranged from 24 to 76 years with 22 males and 16 females. The procedures were done under general anesthesia in prone position on Gardner-Wells pins and a horseshoe headrest. After exposing the pedicles, $3.5 \mathrm{~mm}$ by 22 $\mathrm{mm}$ titanium poly-axial screws where inserted through the pedicles using the technique described by Professor Abumi. The pedicle screws were connected by a connecting rod, which had been bent in accordance with the normal cervical lordosis. Fusion was done using the bones obtained from the spinous process and laminae.

There were fifty-six screws which were mis-directed, and had to be immediately corrected. There was no incidence of significant pedicle penetration or injury to neuro-vascular structures. There was temporary weakness of upper limbs postoperatively in seven patients, which recovered fully in two months' time. There were six deaths due to uncontrolled septicaemia triggered by chest infection. The rest of the patients were discharged between one to six weeks after surgery.

Transpedicular fixation of unstable cervical spine provides biomechanically a very rigid and good correction of sagittal alignment with a high-fusion rate and a few surgical complications. After realizing these advantages, transpedicular screw fixation in cervical spine is becoming an increasingly popular spine surgeon's armamentarium.

Key Words: Cervical spine, pedicle fixation, transpedicular approach

\footnotetext{
$\mathrm{S}$ tabilization and arthrodesis of cervical spine is needed to treat an unstable spine, whether it is due to trauma, tumor, degeneration or postoperatively after decompression. Preserving the delicate anatomy
}

and function of cervical spine while stabilizing, is the real challenge. Since the last 75 years, there has been a constant evolution in terms of technique, material and design of instruments to achieve these goals. There is 
Sharma et al

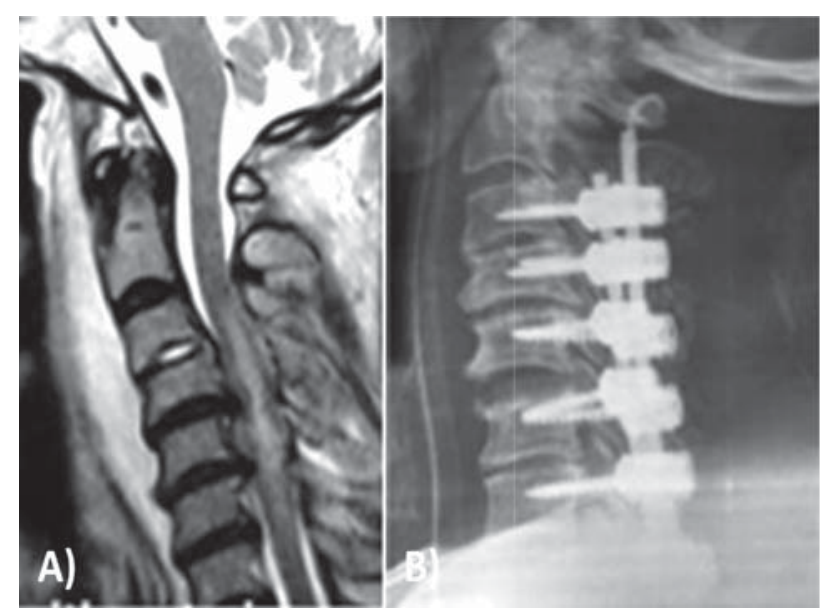

Figure 1: A 70 years gentleman presented with severe neck pain and with quadriparesis of ASIA grade C following an alleged fall. A) MRI showed cord contusion in presence of tight cervical canal with multiple level disc protrusion. B) Cervical laminectomy and transpedicular fixation from C3 to C7 levels.

not much of controversy for anterior pathologies and instrumentations that are approached anteriorly. However, a number of options are available for the posterior approach and instrumentation. Among the posterior approaches, the transpedicular approach to the cervical spine is a relatively new approach with its own merits and demerits. This procedure is more useful in conditions when lamina or lateral masses are inadequate as stabilizing anchors, in cases of osteoporosis or in those cases complicated by previous surgery. ${ }^{7}$ Our experience is shared here.

\section{Materials and Methods}

We had 38 patients with subaxial cervical spine pathologies who underwent transpedicular cervical fixation from February 2014 to September 2015 in Neurosurgery Departments of Nepal Medical College and B \& B Hospital (Table 1). Twenty-four of these cases had unstable spines due to trauma, twelve had severe cervical multilevel spondylotic cord compression with clinical and imaging evidence of myelopathy and two had dump bell schwannomas. The age ranged from 24 to 76 years with 27 males and 11 females.

The trauma cases presented to the emergency department from two hours to three days after the injury. Twelve patients had sustained injury during road traffic accident, eight had a fall from either tree or cliff and four had sustained the injury during physical assaults. Neurologically, out of the twenty-four cases of trauma, four cases had ASIA grade E, 9 cases had ASIA grade D, four cases had ASIA grade $C$, three cases had ASIA grade

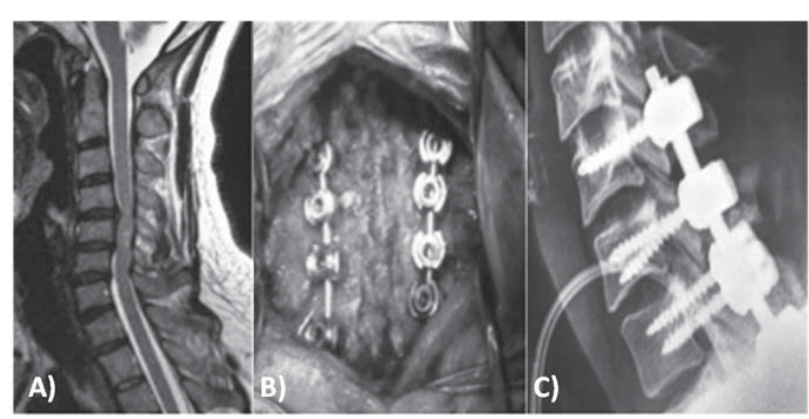

Figure 2: A) MRI showing C4/5 and C5/6 disC protusion with canal stenosis with hyper-intensity of the cord in the region and reverse lardosis. B) Intraoperative picture showing wide laminectomy of C4 to C7and the fixation. C) Postoperative $X$-ray of the cervical spine.

B and four had ASIA grade A. Out of these, five cases had clinical features of central cord syndrome. The respiration was compromised in eleven of these cases. However, none were put on ventilator preoperatively.

All of these patients had X-ray cervical spine of anterio-posterior and lateral views. Eighteen cases out of the 24 trauma cases had CT scan done to assess the pedicular anatomy better. They all underwent MRI scan of cervical spine. Among the trauma cases, six cases had two levels burst fracture without displacement but had cord contusion. Two had multiple level lamina and spinous processes fracture involving Cervico-thoracic junction. Nine patients had multiple level injuries of vertebral bodies, spine and laminae without significant anterior compression. Six of these had evidence of cord contusion. Seven cases had severe cord contusion in presence of severe cervical canal stenosis at multiple levels. All those twelve cases with severe canal stenosis had MRI evidence of myelomalacia. The details of the tumors were shown by MRI in two cases which was suggestive of schwannoma of cervical spine at C3-4 and C 4-5 levels.

They underwent surgery within 48 hours of admission. The procedures were done under general anesthesia in prone position on Gardner-Wells traction and a horseshoe headrest. Through the midline posterior approach, the spinous processes, laminae, the pedicles and the articular processes, up to the lateral mass were exposed between C2 to T3 levels, depending on the levels of fixation needed. The insertion technique of the screws was performed as described by Prof Abumi. The entry point from C3 to C7 spines was $2 \mathrm{~mm}$ below the margin of the superior facet joint, just lateral to the mid-point of the lateral mass or 5 to $6 \mathrm{~mm}$ medial to the lateral edge of the lateral mass. The cortex of the entry point was penetrated by a sharp instrument, called awl. Under a fluoroscope, a hole was drilled through the pedicle into the body of cervical spine 


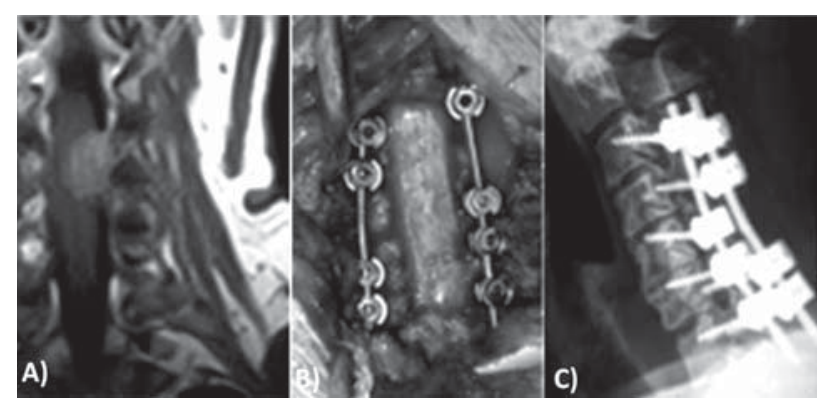

Figure 3: A) MRI showing an enhancing mass having both intra- and extra-dural component and extending through left C3-4 foramina. B) Intraoperative picture of fixation C3 to C7. C) Postoperative X-ray after fixation.

using a $2.7 \mathrm{~mm}$ high-speed drill. A drill was used to avoid further injury by the undue force required to make a track for the screws in an already unstable spine. The direction of the trajectory was 25 to 45 degree medial in the transverse plane and parallel to the superior endplate of the vertebral body in the sagittal plane.

To ensure that the pedicle is not breached, a thin soundprobe was inserted into the hole which ensured bone all around the drilled track. Then titanium cancellous screws of $3.5 \mathrm{~mm}$ by $22 \mathrm{~mm}$ were inserted through the same track. A wide and liberal laminectomy was performed in cases of severe canal stenosis. In cases of tumors, wide and liberal laminectomy was done in the area of tumor. The intradural part of the tumor was first removed followed by the extradural part after closing the dura. After removal of the tumor and/or decompressing the cord well, the pedicle screws were connected by interconnecting rods, which were bent to achieve the normal cervical lordosis. The bone obtained during laminectomy was placed on either side of the rods to achieve fusion. Wound was closed in layers.

All the cases of ASIA grade A and B (seven cases) underwent tracheostomy on the same sitting and they were connected to ventilator support postoperatively. The rest of the cases were extubated and put in ICU postoperatively for close monitoring.

Few cases have been illustrated (Figure 1, 2, 3).

\section{Results}

During the surgery, while drilling the holes, there were fifty-six screws (18.4\%), which were found to be malpositioned. The drills had gone either very near or into the disc spaces. A fresh hole was drilled under the guidance of fluoroscope. There was no incidence of significant pedicle penetration as the track of the drill was rechecked by a sound-probe, which confirmed the tract to be in the bony structure throughout. There were incidences of gush of blood while drilling the tract from the bone marrow. However, there was no incidence of injury to vascular or neural tissues.

Postoperatively, the seven patients of ASIA grade A and $\mathrm{B}$ at admission were connected to ventilatory support. Attempts to wean off the ventilator were started from the next day. Respiratory insufficiency and infection was common in all these patients. Six of these patients progressed to septicaemia, multi-organ failure and ultimately died. Rest of the patients could be weaned off the ventilator and were shifted to the ward. The rest of the patients who were initially managed in ICU for close monitoring of the vitals, were shifted to the ward once they were stabilized. Out of the eight patients who had presented with severe canal stenosis with myelopathy, four developed significant chest infection and they were managed with physiotherapy and appropriate antibiotics. Postoperatively, in seven cases, there was temporary weakness of upper limbs, mainly the deltoid muscle. This could be due to iatrogenic foraminal stenosis, mainly C4-5, which recovered fully in two months' time. There were eleven cases of superficial wound infection, which improved with local care and appropriate antibiotics. The patients were discharged between one to six weeks after surgery on Philadelphia collar.

The follow up of the discharged patients was poor. Only 26 patients came for the first follow up in 2 weeks, and the number gradually reduced in the subsequent follow up in one month, three months, six months and one year. Only eleven cases have come at one-year follow up. Almost all patients had developed bilateral frozen shoulders, which improved with physiotherapy. There were no incidences of screws or rods breakage, loosening, pullout, disassembly, secondary fracture, pseudo-arthosis or loss of correction.

\section{Discussion}

True incidence of cervical injury is not known in Nepal but collectively a large number of the injuries are received every day in emergency department of hospitals at different parts of Nepal. Most of the Nepalese live at a high risk of spinal injuries i.e. unsafe house, unsafe roads and vehicles, unsafe work place with inadequate safety measures, etc. While offering treatment, the socio-economic status and the work or life-style after the treatment has also to be considered. Only one chance and one approach for treatment are available with limited resources in most of the patients. In this context, a rigid fixation which allows them to be discharged early and enabling them to return to work early, needs to be thought of. Over the years, for posterior fixation, we progressed from simple wiring to sublaminar fixation and now to 


\section{Sharma et al}

\begin{tabular}{|c|c|}
\hline Total no. of cases & 38 \\
\hline Duration of study & February 2014 to December 2015 \\
\hline \multicolumn{2}{|l|}{ Etiology } \\
\hline Trauma & 24 \\
\hline Degeneration & 12 \\
\hline Tumor & 2 \\
\hline Age & 24 to 76 years \\
\hline Sex & 22 males and 16 females (11:8) \\
\hline \multicolumn{2}{|l|}{ Presentation } \\
\hline \multicolumn{2}{|l|}{ Trauma } \\
\hline ASIA grade A & 4 \\
\hline ASIA grade B & 3 \\
\hline ASIA grade $\mathrm{C}$ & 4 \\
\hline ASIA grade D & 9 \\
\hline ASIA grade E & 4 \\
\hline Central cord syndrome & 5 \\
\hline Compromised respiration & 11 \\
\hline \multicolumn{2}{|l|}{ Investigations (X-ray, CT Scan and MRI) } \\
\hline \multicolumn{2}{|l|}{ Trauma } \\
\hline $\begin{array}{l}\text { Two and more levels burst fracture } \\
\text { without displacement but had cord } \\
\text { contusion }\end{array}$ & 6 \\
\hline $\begin{array}{l}\text { Multiple level lamina and spinous } \\
\text { processes fracture involving Cervico- } \\
\text { thoracic junction }\end{array}$ & 2 \\
\hline $\begin{array}{l}\text { Multiple level injuries of vertebral } \\
\text { bodies, spine and laminae without } \\
\text { significant anterior compression with } \\
\text { cord contusion }\end{array}$ & 9 \\
\hline $\begin{array}{l}\text { Severe cord contusion in presence of } \\
\text { severe cervical canal stenosis at } \\
\text { multiple levels }\end{array}$ & 7 \\
\hline $\begin{array}{l}\text { Spondylotic myelopathy with severe } \\
\text { cervical canal stenosis }\end{array}$ & 12 \\
\hline \multicolumn{2}{|l|}{ Tumors } \\
\hline $\begin{array}{l}\text { Radiological features of dumb bell } \\
\text { schwannoma at C4-5 and C5-6 levels }\end{array}$ & 2 \\
\hline \multicolumn{2}{|l|}{ Surgery } \\
\hline Transpedicular screw fixation & 38 \\
\hline Tracheostomy & 7 \\
\hline Results & \\
\hline
\end{tabular}


Subaxial Cervical Spine

\begin{tabular}{|l|c|}
\hline Hospital stay & 1 to 6 weeks \\
\hline Complications & 56 screws (18.4\%) \\
\hline Mis-directed screws & None \\
\hline Significant breach in the pedicles & None \\
\hline Neurovascular injuries & 7 (temporary) \\
\hline Postoperative weakness & 12 \\
\hline Chest infection (significant) & None \\
\hline Screw related complications & 6 (Chest infection and septicaemia) \\
\hline Deaths & \\
\hline
\end{tabular}

Table 1: Summary of cases

screw fixation either by lateral mass or transpedicular approaches. ${ }^{18}$ Besides trauma, the procedure can be equally and very effectively used in other pathologies like tumors, degenerative diseases, spondylotic myelopathy and infections to stabilize the spine. ${ }^{1,6,10,11,36}$

Transpedicular fixation of cervical spine is feared and not recommended by many due to the risk of neurovascular injury, small size of the pedicles, the availability of other options like lateral mass fixation and the lack of safety data. Pioneers of posterior cervical spine like, RoyCamille stated that except for placement of transpedicular screws at $\mathrm{C} 2$, placement of transpedicular screws into the C3-C6 pedicle would be an unacceptable risk to the vertebral artery, spinal cord, and nerve roots. ${ }^{41}$ However, with our short experience, we felt that after knowing the cervical anatomy well, strictly following the bony landmarks and using image guidance to insert the screws, though neurovascular complications cannot be completely eliminated, transpedicular screw fixation is relatively safe and carries definitive and unique advantage over all the other procedure. ${ }^{6}$

Historically, transpedicular fixation was first performed in the second cervical spine in 1964 by Leconte ${ }^{30}$ and then in 1979 by Saillant and Bleynia.43 However for subaxial spine, the approach was first used by Abumi and Colleagues in 19944 and by Jeannneret and Colleagues in $1994 .{ }^{19}$ Now the procedure is widely used throughout the world in different pathologies like trauma, tumor, degeneration, infection, etc ${ }^{5,6}$ This technique relies on anatomical landmarks and accurate knowledge of the pedicles in relation to the vertebral artery and the nerve roots. ${ }^{13,19,23}$

There are some very distinct advantages of transpedicular approach when used in cervical spine. In the transpedicular procedure, the trajectory involves all the three columns of cervical spine. ${ }^{21,32}$ The screw traverses from the pedicle into the vertebral body from either side fixing all the three columns of spine as described by Denish. ${ }^{14}$ The screw also passes through the strongest component of the spine, i.e. the pedicle and the vertebral body. ${ }^{26}$ The fixation is therefore biomechanically very strong and rigid. ${ }^{4,21,25,27,29,44}$

With the length of the screw, angle used to put the screw i.e. 45 degrees and the direction of the traction exerted i.e. 90 degrees, the chance of screw pulling out is very minimal compared to other procedures. ${ }^{20,21,46}$ Mean load to failure was significantly lower in pedicle screws (677 N) compared to that in lateral mass screws fixation (355 N). Thus the procedure has a high pullout resistances and significantly higher axial load-to-failure. ${ }^{42}$ The procedure has significantly lower rate of loosening at the bone screw interface and a higher strength after fatigue testing. ${ }^{17,20}$ Thus transpedicular fixation can be done even in osteoporotic bones with a good fusion rate.

Transpedicular fixation of cervical spine is considered now-a-days the most advantageous instrumentation in correction of flexible cervical kyphosis with preserved segmental motion. ${ }^{5,7}$ It assists in correcting or preventing additional changes in spinal alignment, enhances fusion rates and allows early mobilization of the patient without the need for cumbersome external immobilization for long. ${ }^{5,3,7}$ In some pathologies, where both anterior and posterior approaches are needed, the spine can be effectively stablised with pedicle screw fixation obviating the need for anterior surgery. ${ }^{7,8,9}$

In cases of severe cervical canal stenosis with reversed lordosis, the teaching so far was to decompress the spine anteriorly by multilevel corpectomy and fix anteriorly with cages and plates. With transpedicular approach, the cervical spinal canal is widely opened after liberal laminectomy and then fixed posteriorly rigidly with pedicle screws, reestablishing the normal cervical lordosis by connecting the screws with a connecting rod, which is appropriately bent in accordance to the cervical curvature. ${ }^{1,10,28}$ The approach can thus be used in deformity correction as well. Cervical laminectomy with transpedicular insertion technique is known to be a single staged biomechanically stronger method in cervical pathologies. ${ }^{6,7,11}$ 


\section{Sharma et al}

The point of entry of the screws is $3 \mathrm{~mm}$ lateral to the midline of the lateral mass and trajectory is directed from lateral to medical direction. This gives an extra and adequate space for a wide laminectomy in case of severe canal stenosis and in cases of tumor resection where one may need to go as lateral as possible. In cervical spondylotic myelopathy with severe canal stenosis, laminoplasty is suggested since long but when it is combined with transpedicular screw fixation, the long term result have been shown to be better as it not only stabilizes but also corrects and maintain normal alignment of cervical spine. ${ }^{34}$ In "re-do" cases where patients have already undergone laminectomy, cervical spine can still be stabilized by transpedicular approach because in this approach lamina is not needed as stabilizing anchor. ${ }^{10}$

The injury at cervico-thoracic junction is difficult to fix anteriorly, particularly if the patient has a short neck. Cervico-thoracic junction being the junction of mobile and a rigid segment of spine, a rigid fixation is necessary, as the region has to bear a significant force during movement. Such a spine can be fixed posteriorly using transpedicular approach very rigidly without incidence of pseudoarthrosis or loosening of the screws. ${ }^{12,13,37}$

The main complication associated with transpedicular fixation is breach in the pedicles with high chance of neurovascular complications. ${ }^{24}$ To prevent the screw breaching the pedicle and the subsequent complications, the anatomy of the pedicles and vertebral artery have to be studied very carefully by CT scan, CT or MR angiogram and MRI. ${ }^{35}$ Different ways have been described to pass the screws through the pedicles into the vertebral bodies without breaching the pedicle and preserving neurovascular structures. The initial techniques were based on the surface markings of the posterior elements of cervical spine. Abumi et al opened the articular mass down to the introitus of the pedicle4 and probed the pedicle. Karaikovic et al. ${ }^{23}$ used a modified funnel technique and then inserted the screw under fluoroscopy guidance. Compared to fluoroscopy-guided insertion, the accuracy of pedicle screw insertion through the pedicle into the vertebral body is reported to be better with direct palpation after laminotomy or partial laminectomy ${ }^{33,38}$ and best with computer-assisted placement. ${ }^{22,25,31,39,40}$ Such a computer navigation system or neuro-navigation system is not usually available in most of the institutes including ours. However, directing the screw under fluoroscopy can give a comparable result. ${ }^{47}$ There has been report of free hand placement of the screws but the incidence of misdirection, misplacement, neuro-vascular injury was very high and is not recommended. ${ }^{45}$ The overall incidence of malposition has been quoted to be between 16 to $26 \%$. $^{16,31}$ The incidence of significant misplacement of the screws requiring re-insertion with fluoroscopy guidance in our series was $18.4 \%$.

In seven cases, there was weakness of deltoid muscles (C5 root) postoperatively. This has been described to be due to further narrowing of a pre-existing foraminal stenosis and excessive reduction of translational deformity during fixing of the screws tightly.,15 The temporary weakness of the deltoid muscle gradually improved with physiotherapy. In these cases, during surgery foraminal decompression (foraminotomy) is recommended before tightening the pedicle screws.

\section{Conclusions}

Transpedicular fixation of unstable cervical spine provides a good correction of sagittal alignment, has a high-fusion rate and a few surgical complications. It provides the most rigid posterior fixation technique with superior stability and resistance to screw pullout. Though being considered by some to be a high unacceptable risk surgery, with good anatomical knowledge and methodical procedure, it has minimal chance of neurovascular compromise and is a good and safe surgery. After realizing these advantages, transpedicular screw fixation in cervical spine is becoming a popular spine surgeon's armamentarium.

\section{Conflict of interest}

Author declares that there is no actual or potential conflict of interest with organizations in relation to this article.

\section{References}

1. Abumi K. Cervical spondylotic myelopathy: posterior decompression and pedicle screw fixation. European Spine Journal 24: 186-196, 2015

2. Abumi K, Ito M, Kaneda K. Surgical treatment of cervical destructive spondyloarthropathy (DSA). Spine 25: 2899-2905, 2000

3. Abumi K, Ito $\mathrm{M}$, Sudo $\mathrm{H}$. Reconstruction of the subaxial cervical spine using pedicle screw instrumentation. Spine 37: 349-356, 2012

4. Abumi K, Itoh $\mathrm{H}$, Taneichi H, Kaneda $\mathrm{K}$. Transpedicular screw fixation for traumatic lesions of the middle and lower cervical spine: description of the techniques and preliminary report. $\mathbf{J}$ Spinal Disord 7: 19-28, 1994

5. Abumi K, Kaneda K. Transpedicular screw fixation for reconstruction of the cervical spine; Proceedings of the 62nd Meeting of the American Academy of Orthopedic Surgeons: Orland, FL, USA, 1995 
6. Abumi K, Kaneda K. Pedicle screw fixation for non-traumatic lesions of the cervical spine. Spine 22(16): 1853-1863, 1997

7. Abumi K, Kaneda K, Shono Y, Fujiya M. Onestage posterior decompression and reconstruction of the cervical spine by using pedicle screw fixation systems. J Neurosurg 90: 19-26, 1999

8. Abumi K, Shono Y, Ito M, et al. Complications of pedicle screw fixation in reconstructive surgery of the cervical spine. Spine 25(8): 962-969, 2000

9. Abumi K, Shono Y, Kotani Y, et al. Indirect posterior reduction and fusion of the traumatic herniated disc by using a cervical pedicle screw system. J Neurosurg 92: 30-37, 2000

10. Abumi K, Shono Y, Taneichi H, Ito M, Kaneda K. Correction of cervical kyphosis using pedicle screw fixation systems. Spine 24(22): 2389-2396, 1999

11. Abumi K, Takada T, Shono Y, Kaneda K, Fujiya M. Posterior occipitocervical reconstruction using cervical pedicle screws and plate-rod systems. Spine 24(14): 1425-1434, 1999

12. Albert TJ, Klein GR, Joffe D, Vaccaros AR. Use of cervicothoracic junction pedicle screws for reconstruction of complex cervical spine pathology. Spine 23(14): 1596-1599, 1998

13. Barrey C, Cotton F, Jund J, Mertens P, Perrin G. Transpedicular screwing of the seventh cervical vertebra: anatomical considerations and surgical technique. Surg Radiol Anat 25(5-6): 354-360, 2003

14. Denis F. Spinal instability as defined by the threecolumn spine concept in acute spinal trauma. Clin Orthop Relat Res (189): 65-76, 1984

15. Heller JG, Silcox DH III, Sutterlin CE III. Complications of posterior cervical plating. Spine 20(22): 2442-2448, 1995

16. Hojo Y, Ito M, Suda K, Oda I, Yoshimoto H, Abumi K. A multicenter study on accuracy and complications of freehand placement of cervical pedicle screws under lateral fluoroscopy in different pathological conditions: CT-based evaluation of more than 1,000 screws. Eur Spine J 23(10): 2166-2174, 2014

17. Ito Z, Higashino K, Kato S, Kim SS, Wong E, Yoshioka K, Hutton WC. Pedicle screws can be 4 times stronger than lateral mass screws for insertion in the midcervical spine: a biomechanical study on strength of fixation. J Spinal Disord Tech 27(2): 80-85, 2014

18. James K. Liu, Kaushik Das, MD. Posterior Fusion of the Subaxial Cervical Spine: Indications and Techniques. Neurosurg Focus 10(4): E7, 2001

19. Jeanneret B, Gebhard JS, Magerl F. Transpedicular screw fixation of articular mass fracture-separation: Results of an anatomical study and operative technique. J Spinal Disord 7(3): 222-229, 1994

20. Johnston TL, Karaikovic EE, Lautenschlager EP, Marcu D. Cervical pedicle screws vs. lateral mass screws: uniplanar fatigue analysis and residual pullout strengths. Spine J 6(6): 667-672, 2006

21. Jones EL, Heller JG, Silcox DH, Hutton WC. Cervical pedicle screws versus lateral mass screws. Anatomic feasibility and biomechanical comparison. Spine 22(9): 977-982, 1997

22. Kamimura M, Ebara S, Itoh H, Tateiwa Y, Kinoshita T, Takaoka K. Cervical pedicle screw insertion: assessment of safety and accuracy with computerassisted image guidance. J Spinal Disord 13(3): 218-224, 2000

23. Karaikovic EE, Kunakornsawat S, Daubs MD, Madsen TW, Gaines RW Jr. Surgical anatomy of the cervical pedicles: landmarks for posterior cervical pedicle entrance localization. J Spinal Disord 13(1): 63-72, 2000

24. Kast E, Mohr K, Richter HP, Börm W. Complications of transpedicular screw fixation in the cervical spine. Eur Spin J 15(3): 327-334, 2006

25. Kotani Y, Abumi K, Ito M, Minami A. Improved accuracy of computer-assisted cervical pedicle screw insertion. J Neurosurg 99: 257-263, 2003

26. Kotani Y, Cunningham BW, Abumi K, McAfee PC. Biomechanical analysis of cervical stabilization systems. An assessment of transpedicular screw fixation in the cervical spine. Spine 19(22): 25292539, 1994

27. Kothe R, Ruther W, Schneider E, Linke B. Biomechanical analysis of transpedicular screw fixation in the subaxial cervical spine. Spine 29(17): 1869-1875, 2004

28. Kotil K, Ozyuvaci E. Multilevel decompressive laminectomy and transpedicular instrumented fusion for cervical spondylotic radiculopathy and myelopathy: A minimum follow-up of 3 years. $\mathbf{J}$ Craniovertebr Junction Spine 2(1): 27-31, 2011

29. Kowalski JM, Ludwig SC, Hutton WC, Heller JG. Cervical spine pedicle screws: a biomechanical comparison of two insertion techniques. Spine 25(22): 2865-2867, 2000

30. Leconte P. Fracture et luxation des deux premières vertèbres cervicales. In: Judet R, editor. Luxation Congenénitale de la Hanche: Fractures du Coude-pied Rachis Cervical. Actualités de Chirurgie Orthopédique de l’Hö pital Raymond-Poincaré. Paris: Masson et Cie: 147-166, 1964 (French)

31. Ludwig SC, Kowalski JM, Edwards CC 2nd, Heller 


\section{Sharma et al}

JG. Cervical pedicle screws: Comparative accuracy of two insertion techniques. Spine 25(20): 2675-81, 2000

32. Ludwig SC, Kramer DL, Vaccaro AR, Albert TJ, Transpedicle screw fixation of the cervical spine. Clin Orthop Relat Res 359: 77-88, 1999

33. Miller RM, Ebraheim NA, Xu R, Yeasting RA. Anatomic consideration of transpedicular screw placement in the cervical spine. An analysis of two approaches. Spine 21(20): 2317-2322, 1996

34. Miyamoto H, Maeno K, Uno K, Kakutani K, Nishida $\mathrm{K}$, Sumi M. Outcomes of surgical intervention for cervical spondylotic myelopathy accompanying local kyphosis (comparison between laminoplasty alone and posterior reconstruction using the screwrod system). Eur Spine J 23(2): 341-346, 2014

35. Mohi Eldin MM. Cervical Pedicle Screw Fixation: Anatomic Feasibility of Pedicle Morphology and Radiologic Evaluation of the Anatomical Measurements. Asian Spine J 8(3): 273-280, 2014

36. Oda I, Abumi K, Ito M, Kotani Y, Oya T, Hasegawa $\mathrm{K}$, Minami A. Palliative spinal reconstruction using cervical pedicle screws for metastatic lesions of the spine: a retrospective analysis of 32 cases. Spine 31(13): 1439-1444, 2006

37. Pelton MA, Schwartz J, Singh K. Subaxial cervical and cervicothoracic fixation techniques--indications, techniques, and outcomes. Orthop Clin North Am 43(1):19-28, 2012

38. Reinhold M, Magerl F, Rieger M, Blauth M. Cervical pedicle screw placement: feasibility and accuracy of two new insertion techniques based on morphometric data. Eur Spine J 16(1): 47-56, 2007

39. Richter M, Cakir B, Schmidt R. Cervical Pedicle Screws: Conventional Versus Computer-Assisted Placement of Cannulated Screws. Spine 30(20): 2280-2287, 2005
40. Richter M, Mattes T, Cakir B. Computer-assisted posterior instrumentation of the cervical and cervicothoracic spine. Eur Spine J 13(1): 50-59, 2004

41. Roy-Camille R, Saillant G, Mazel C. Internal fixation of the unstable cervical spine by a posterior osteosynthesis with plates and screws. The Cervical Spine. Edited by the Cervical Spine Research Society. Philadelphia, JB Lippincott Co, 1989, pp 390-403

42. Rumi MN, Kowalski JM, Gelb DE, et al. Rationale for cervical pedicle screw placement in the subaxial spine. Curr Opin Orthop 12: 265-273, 2001

43. Saillant G, Bleynie JF. Fracture des pedicules de l'axis. In: Roy-Camille R, ed. Rachis Cervical Traumatique Non Neurologique. Pathologie Traumatique de 1'Epaule et de la Ceiture Scapulaire. Paris: Masson: 88-98, 1979 (French)

44. Schmidt R, Wilke HJ, Claes L, Puhl W, Richter M. Pedicle screw enhance primary stability in multilevel cervical corpectomies: Biomechanical in vitro comparison of different implants including constrained and nonconstrained posterior instrumentation. Spine 28(16): 1821-1828, 2003

45. Xu RM, Ma WH, Wang Q, Zhao LJ, Hu Y, Sun SH. A free-hand technique for pedicle screw placement in the lower cervical spine. Orthop Surg 1(2): 107 112, 2009

46. Yukawa Y, Kato F, Ito K, et al. Placement and complications of cervical pedicle screws in 144 cervical trauma patients using pedicle axis view techniques by fluoroscope. Eur Spine J 18(9): 1293-1299, 2009

47. Yukawa Y, Kato F, Yoshihara H, Yanase M, Ito K. Cervical pedicle screw fixation in 100 cases of unstable cervical injuries: pedicle axis views obtained using fluoroscopy. J Neurosurg Spine 5(6): 488-493, 2006 